\title{
Exploring the Lateral Capacity of Squat Piles in Soft Clay Through Geotechnical Centrifuge Modelling
}

\author{
K. Hein \& G. Biscontin \\ Schofield Centre \\ University of Cambridge \\ Cambridge, UK
}

\author{
F.J. Grajales S. \& C.P. Aubeny \\ Zachry Dep. of Civil Engineering \\ Texas A\&M University \\ College Station, Texas, USA
}

\author{
R.D. Beemer \\ COFS \\ University of Western Australia \\ Perth, Australia
}

\begin{abstract}
Many offshore structures currently in use are supported by piles with large length-to-diameter aspect ratios, because it is well known that such foundations can hold large forces and moments. In environments where long piles are not suitable, structures will use foundations with very low aspect ratios such as skirts and mats. Capacity of long piles has been studied for decades and is well documented, whilst more recent tests have also addressed the behaviour of skirts, mats, and other low-aspect ratio foundations. The vertical and lateral capacity of mid-size foundations, with aspect ratios between one and five, has generally been thought too low for the requirements of most offshore structures. However, in recent years, structures of increasingly different shapes and sizes have been used in offshore environments, such as water-based renewable energy sources or marginal oil and gas platforms. In many of these cases, the usage of a low aspect ratio foundation could significantly reduce installation and transportation costs. Limited studies have been performed on such foundations, and most of the existing work uses only analytical and numerical solutions. Geotechnical centrifuge tests and corresponding numerical analyses were started at Texas A\&M University and were continued at the University of Cambridge on the lateral capacity of piles with an aspect ratio of two in normally consolidated clay. Piles were loaded under both pure rotation and a mix of rotation and translation. This work is relevant to offshore structures requiring foundations that are strong but easily installed and cost-efficient, specifically structures secured with piles that experience point loads either through or above the water. It is also of interest for structures in difficult environments, such as areas too shallow or sedimentary for long piles or too fragile for skirts and mats.
\end{abstract}

Keywords-Piles, Caissons, Geotechnical Centrifuge, Lateral Capacity, Finite Element Method

\section{INTRODUCTION AND BACKGROUND}

The number of offshore facilities in use and in development is increasing around the UK and around the world, including traditional and non-traditional oil and gas infrastructure, alternative energy structures, marginal or developmental oil rigs, and recreational structures. Many of these structures require lightweight, low-cost foundations, for which lowaspect ratio piles could work well. Such wide variation in facilities and needs easily justifies matching the best foundation to each new application to further increase the effectiveness of the structure and decrease its cost.

Project Sponsored by the National Science Foundation, Project: NEESRCR: Capacity and Performance of Foundations for Offshore Wind Towers. Award 1041604
Most offshore structures are either vertically supported or anchored to the seabed, depending on the water depth at the desired site. Tall structures such as offshore wind turbines installed in relatively shallow water are often supported on either long monopiles or multi-pile arrangements of shorter caissons, whereas extended structures require many short and wide piles. Structures in deep water rely on floating systems, which could be anchored to the seabed using piles or caissons.

Foundation classification varies by soil; the softer the soil, the more rigidly a foundation will respond. Foundations with aspect ratios larger than 10 in soft clay are classified as "flexible", while foundations with low aspect ratios are typically considered "rigid" $[1,2]$ as shown in Fig. 1. Previous work on piles with aspect ratios greater than 3 use the terms "pile" or "monopile", while work on foundations with aspect ratios lower than one have used "bucket", "skirted foundation", or "mat". The foundations tested in this work are hollow, cylindrical caissons that most look and act like piles and are referred to in this work as "squat piles". A single squat pile would be sufficient for structures with low lateral loads, such as moving surface platforms or hydrokinetic structures. For structures like wind turbines, with large lateral loads at high eccentricities, squat piles could work in multi-legged systems like tripods or tetrapods.

Long piles have been studied for decades. One of the earliest studies were Hudson Matlock's [3] field tests on piles with aspect ratios of 6 and 40 in 1970. Numerous works have followed, such as Hoadley, Barton, \& Perry's 1981 work studying cyclic lateral loading of piles in sand [4]. Mayne, Kulhawy, \& Trautmann [5] performed lateral-load experiments on drill shaft piles in cohesive soils in 1995, using aspect ratios between 3 and 8. Poulos and Davis [1] analytically examined the response of piles with aspect ratios from 10 up to 100 . In more recent history, Lau [6] studied the lateral capacity and hysteresis of piles with an aspect ratio of 4.75 in overconsolidated clay in 2015. Zhang, White, and Randolph published on cyclic lateral loading in soft clay of piles with an aspect ratio of 5 in 2011 [7]. Their work focused on the clay's stiffness and reconsolidation through cyclic loading in centrifuge testing.

Work has also been performed recently on foundations with small aspect ratios. Houlsby, Kelly, Huxtable, \& Byrne [8] conducted field tests on skirts with aspect ratios of 0.5 and 0.67 in 2005, studying lateral and moment loads on a skirt 
foundation. Zhu, Kong, Chen, Kong, \& Chen [9] tested skirts with aspect ratios of 0.5 in silt, in 2011. Their work developed a capacity-based design method, identified the failure points of the structure, and analysed the installation process. In 2009, Brødbæk et al. examined the response difference between flexible and rigid piles [10]. They found that the bottom of rigid piles "kick" due to the shear force generated at the bottom, while flexible piles bend. Work was recently published by Murali [11] on piles in normally consolidated clay with an aspect ratio of 2 . That work is complementary to this paper, and as such it will be referenced and compared to throughout this text.

In addition to centrifuge or field testing, it is possible to model foundations with finite element analysis. Brown and Shie in 1990 [12] and Trochanis et al. in 1991 [13] were among the first to investigate laterally-loaded piles with finite-element modelling. Kim and Jeong [14] analysed the soil resistance of long piles in clay, as well as piles with shorter aspect ratios of 8, 4, and 2.7. Grajales [15] performed finite-element analysis on piles with an aspect ratio of 2 . After finding capacity values using Abaqus-based FE models, Grajales applied a minimising algorithm using Murff and Hamilton's 1993 calculations [16] to find more realistic values.

Many of these publications focus on the pile's capacity, plotting the normalised resistance $p$ of the soil against the normalised displacement $y$ of the pile, resulting in a bearing pressure per unit length $p_{u}$. While there are many methods to modelling $p-y$ curves, the most common approach is from Matlock's 1970 paper [3]:

$$
p_{u}=N_{p} s_{u} D
$$

with a bearing factor $N_{p}$ that varies with the pile depth from the soil surface, soil strength $s_{u}$, and pile diameter $D$. This work did not directly measure linear pressure against the pile or displacement with depth, so Matlock's work is not directly applicable. Matlock's work has been re-examined many times. Stevens and Audibert [17] found that Matlock overestimated a pile's deflection for cohesive soils, and that his overestimation increased with pile diameter. Randolph and Houlsby calculated an upper-bound solution in 1984 [18], which was updated by Martin and Randolph in 2006 [19]. Murff and Hamilton's 1993 work [16] expanded Matlock to incorporate other aspects of the environment, such as soil-pile adhesion and suction for cohesive soils. Their work consisted of a three-dimensional failure mechanism which comprised a conical failure wedge, a flow around zone and a hemispherical failure surface at the pile tip. Internal energy dissipation rates were then computed based on the failure mechanism and equated to external work. As a result, load could be determined. To simplify their analysis, Murff and Hamilton [16] presented an empirical fit which resembled results previously obtained by the complete failure mechanism. By accounting for more variables, they made Matlocks' curves more robust, and provided a different form of calculation by integrating $p$ over the pile length to find the lateral load against the pile $P$. Pile capacity is often displayed by plotting $P$ against normalized lateral displacement $y$. This work was designed for Murff and Hamilton's calculations, which will therefore be referenced through the text.
Despite Murff and Hamilton's improvements, $p-y$ curves have not been sufficiently validated for squat piles and are not reliable for immediate use. With the potential significance of squat piles in offshore developments, the models and calculations must be better explored to be more reliably used.

Figure 2 presents a summary of results previously obtained by Murali [11] and Grajales [15] for piles with aspect ratio of 2, in which piles were laterally loaded and vertically unconstrained. The gray triangles correspond to data for a pile with an eccentricity of $1.5 D$ [11]. Load-displacement curves from FE analyses are presented for limiting adhesions of 0 and 1. MurffHamilton's method [16] is also included for comparison and is presented in black continuous lines.

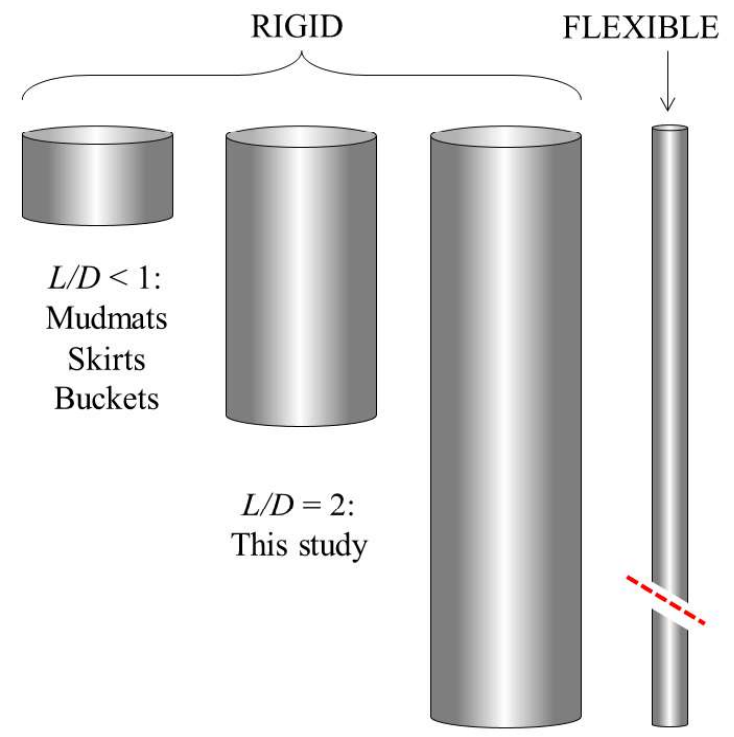

$3<L / D<10$ :

Typically used as monopiles.

Fig. 1. Pile foundations according to aspect ratio

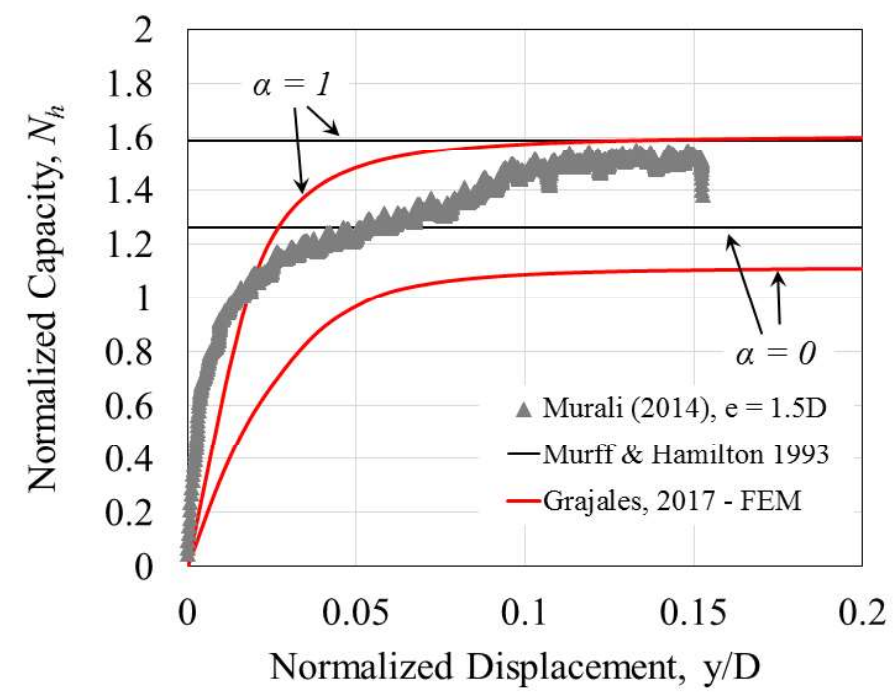

Fig. 2. Load-displacement curves for a piles with aspect ratios of 2. Redrawn from Murali [11] and Grajales [15]. 
It can be clearly observed that the experimental data is bounded by both the upper bound solution [16] and the FE predictions [15]. The piles in this study have been constrained against vertical displacement. This should result in slightly lower capacities than Murali's [11] experiments, but eliminates any increase in strength as the pile sinks.

\section{Centrifuge Testing}

\section{A. Test Setup}

Seven piles were loaded in two separate tests: four piles in the first test, three in the second. The first test held two translated-rotated piles, and two rotated piles at eccentricities $1.4 D$ and $2 D$. The second test held two translated piles and one rotated pile at eccentricity $1.4 D$. Tests were conducted in a steel tub $400 \mathrm{~mm}$ deep and $850 \mathrm{~mm}$ in diameter. The tub was loaded with clay slurry, and the bottom subjected to vacuum suction for three weeks. The suction formed normally consolidated clay with very little stress on top and maximum consolidation stress at the clay bottom. In-flight clay strength was calculated using the SHANSEP method [20]:

$$
\left(s_{u} / \sigma^{\prime}{ }_{v}\right)=S \cdot O C R^{m}
$$

With $S$ from Skempton [21, 22], using the plasticity index PI for specswhite kaolin.

$$
S=0.11+0.37 P I
$$

Table 1 lists all other properties [6], and Fig. 3 plots strength $s_{u O C}$ by depth, scaled to the prototype environment. Consolidation took about three weeks for each model, at which point Measurement Specialties ${ }^{\mathrm{TM}}$ pore pressure transducers were installed at 3 heights in the centre of the clay to track clay pore pressure dissipation in-flight.

The piles were then inserted in the clay. They were 103 mm-long aluminium tubes with $50.8 \mathrm{~mm}$ (2") outer diameters, $3.25 \mathrm{~mm}$ thick. Each pile had a $13 \mathrm{~mm}$-thick cap. A 3D-printed platform was screwed above the cap, with a marker for a laser to measure distance on one side and a microelectricalmechanical sensor (MEMS) on the other. A steel rod wired with strain gauges connected each pile to a sled, forcing the piles to move together as shown in Fig. 4. The sled was connected to a 2-dimensional linear actuator [23], which moved the piles during testing. The piles were held with a moment-less free-rotation connection (Fig. 5) if they were solely rotated in-flight, and bolted to the sled if they underwent both rotation and translation. Fig. 6 shows the fully-assembled tub, ready to be mounted in the centrifuge. Each test consolidated for $4 \frac{1}{2}$ hours (or 2.7 years in the prototype environment), followed by 90 minutes of testing.

Four piles ran in the first test, with 3.4 pile diameters between them. Strain data from the first test peaked as the piles were moved and fell sharply as the pile stabilized, implying the piles might have suffered from group affects. To eliminate this, the second test was reduced to three piles. The second test showed the same results, as did outside sources, and results looked similar between the tests. This implied that

the first data did not experience group affect, so both sets of results were used with the same confidence in all calculations.

\section{B. Experimental Calculations}

Strain gauge, MEMS, laser and LVDT data were combined to find the piles' lateral and moment capacity.

The MEMS' voltage output changes with a change in gravity. As each pile is laterally loaded, it tilts, which changes the gravity it feels. The relationship between the piles' output and its g-level, therefore, can be manipulated to find the tilt of each pile through loading, as presented by Beemer [24]. While tilt was not used in the experimental calculation of capacity, capacity was plotted against tilt while comparing data.

TABLE I.

\begin{tabular}{|c|c|c|}
\hline Symbol & Name & Value \\
\hline$\sigma^{\prime}{ }_{\mathrm{v}, \mathrm{oc}}$ & Consolidation stress, $\mathrm{kPa}$ & $\mathrm{Ng}\left(\rho_{\text {clay }}-\rho_{w}\right)$ \\
\hline $\mathrm{PI}$ & Plasticity index, specswhite kaolin & 0.33 \\
\hline$\lambda$ & Normal-consolidation line slope & 0.22 \\
\hline$\kappa$ & Unload-reload line slope & 0.039 \\
\hline $\mathrm{m}$ & Soil parameter $(\lambda-\kappa) / \lambda$ & 0.84 \\
\hline OCR & Overconsolidation ratio & $\left(\sigma^{\prime}{ }_{v, O C} / \sigma^{\prime}{ }_{e f f}\right)$ \\
\hline
\end{tabular}

\section{Undrained Shear Strength, $s_{u}(\mathrm{kPa})$} 0 5 10

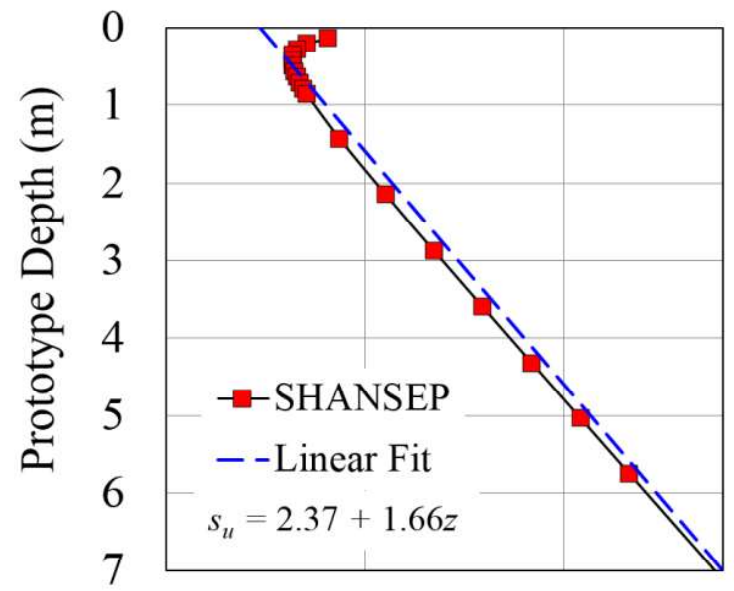

Fig. 3. Clay strength profile, SHANSEP method and linear fit

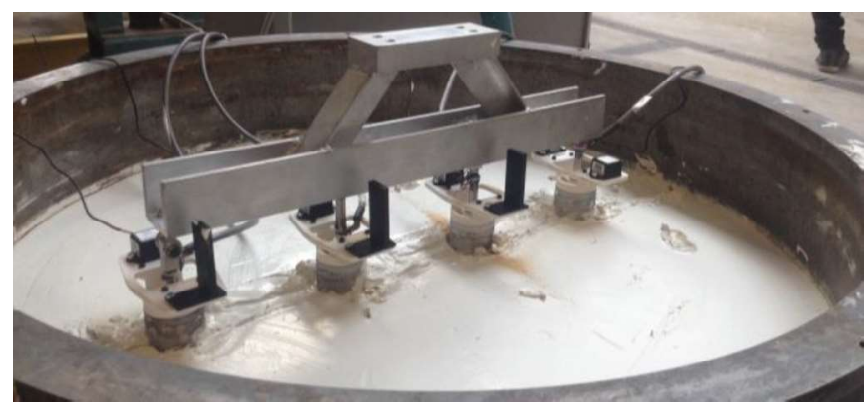

Fig. 4. Piles inserted in the clay testbed, before placement of the actuator. 


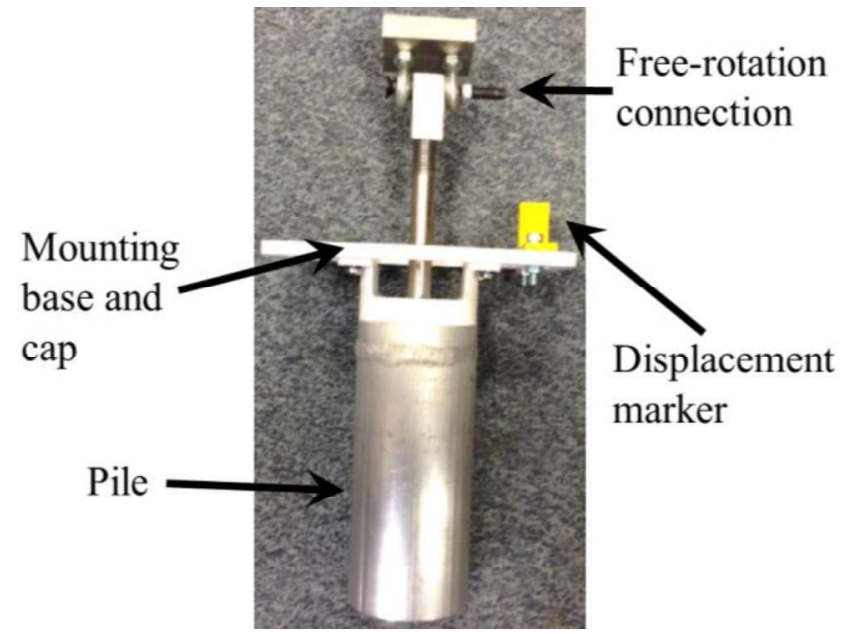

Fig. 5. Model pile with free-rotation connection setup.

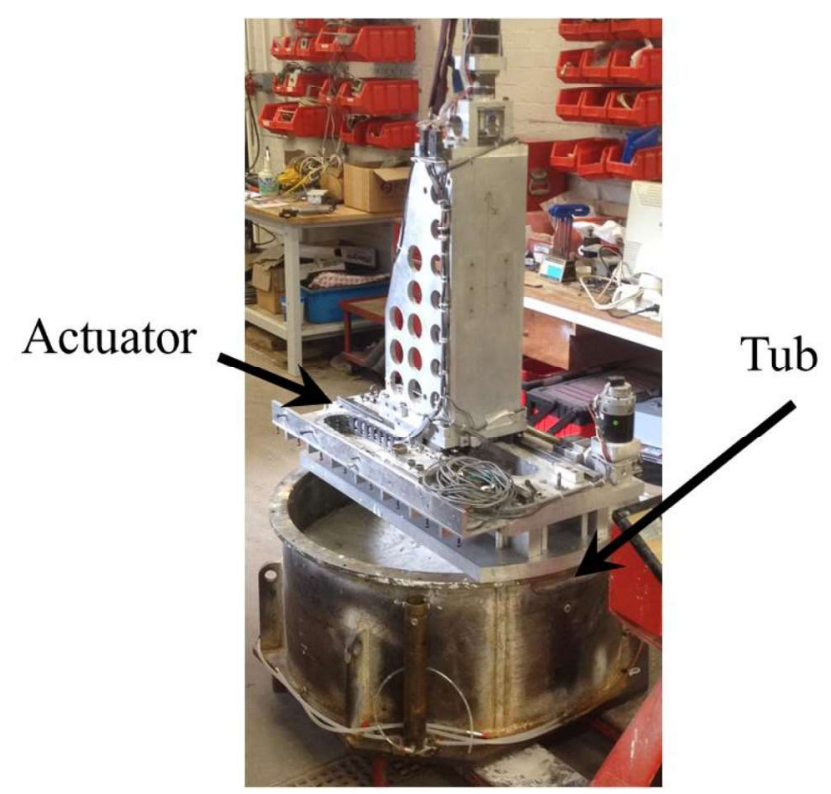

Fig. 6. Tub, piles inserted and actuator mounted

Linear-variable displacement transducers (LVDT) were used in the first test, to track the displacement of the piles through loading. Due to the high g-levels, some of the LVDTs malfunctioned. To mitigate this problem, all LVDTs were replaced by lasers for the second test.

Pile capacity was calculated from the strain gauges mounted on the piles. Three gauges were mounted on each stem; one gauge directly in the direction of loading, the other two rotated 120 degrees. From this configuration, stem curvature $K$ was calculated using the strain measurements of the different gauges, e.g $\varepsilon_{1}$ and $\varepsilon_{2}$ and the lateral difference $\mathrm{s}$ between them. Moment of curvature $M_{k}$ was calculated by multiplying curvature by the modulus of elasticity $E$ and moment of inertia $I$ of the pile stem.

$$
\begin{gathered}
K=\left(\varepsilon_{1}-\varepsilon_{2}\right) / s \\
M_{k}=K E I
\end{gathered}
$$

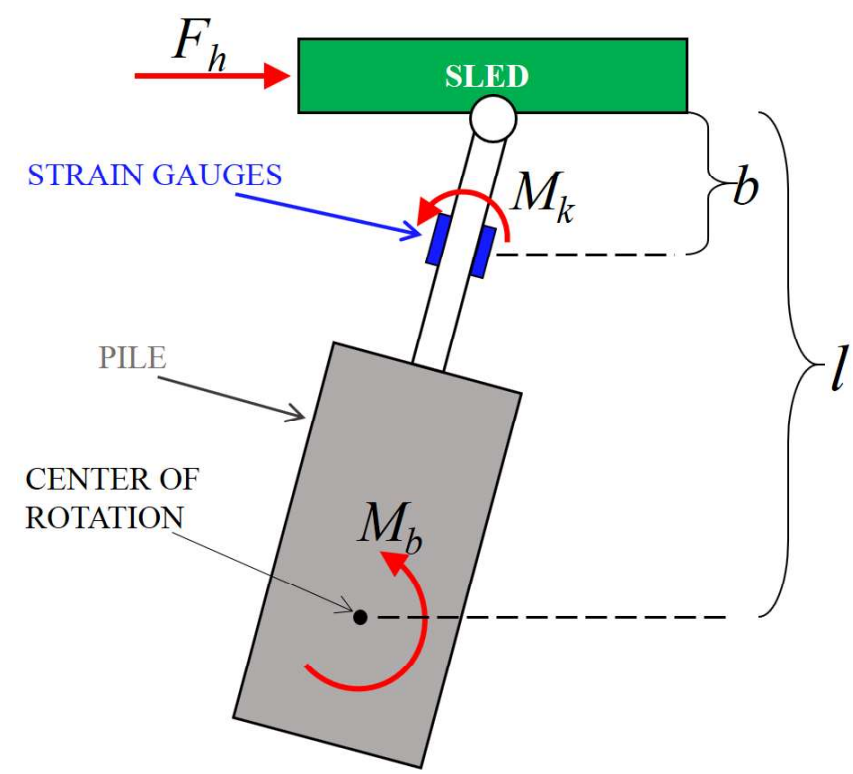

Fig. 7. Pile model for calculating lateral and moment capacity

The piles were embedded in the clay and loaded via displacement at the sled. Because the piles were attached with a frictionless rotational head, the loading is considered to consist of a force $F_{h}$ on a cantilevered beam, secured at the clay's centre of strength (Fig. 7). Force $F_{h}$ is found by dividing the moment of curvature by the moment arm, from the application of force to the moment. Bending moment $M_{b}$, referring to the moment capacity of the pile, is the piles' reaction moment at its fixed position in the clay: $F_{h}$ multiplied by the moment arm from the load application to the piles' fixed position.

$$
\begin{gathered}
F_{h}=M_{k} / b \\
M_{b}=F_{h} l
\end{gathered}
$$

The point of rotation of each pile can be found according to each pile's tilt. Pile capacity is calculated as the maximum normalised load and moment of each pile, using the crosssectional area of the pile diameter $D$ and length $L$ and the average undrained shear strength along the pile $\left(s_{u-a v g}\right)$. Using these methods, lateral and moment capacity values are calculated and compared through FE to Murff and Hamilton's original derivations.

$$
\begin{gathered}
N_{h}=F_{h} /\left(s_{u-a v g} D L\right) \\
N_{m}=M_{b} /\left(s_{u-a v g} D L^{2}\right)
\end{gathered}
$$

\section{NUMERICAL MODELLING}

A finite element (FE) model was used to verify the accuracy of the results obtained through centrifuge testing, developed by Grajales [15] using the software Abaqus, v6.12 [25]. The model has been validated against rigorous plasticity solutions and to some extent against both centrifuge and experimental data [15]. 
The pile is modelled in the FEA as a rigid structure embedded in an isotropic, rate-independent and homogenous soil medium. A Mohr-Coulomb material model was used, with friction angle set equal to zero. No post-yield hardening was allowed. Rigidity index $\left(I_{r}=G / s_{u}\right)$ was set to 50, which corresponds to ranges typical of very soft clays as presented by Vesic [26]. A linearly increasing soil profile was assumed, similar to the linear fit in Fig. 3. Adhesion in the soil-pile interface was initially set to $\alpha=0.65$, as recommended by Andersen [27], but can be changed depending on the specificities of the test. A buoyant unit weight of $5 \mathrm{kN} / \mathrm{m}^{3}$ was assumed.

The FE model was configured to allow gapping. The formation of gaps behind laterally loaded piles is a not very well defined phenomenon. While relatively large gaps are commonly formed behind piles in 1-g laboratory tests, they have not been observed often during centrifuge tests on normally consolidated clays. An in-flight camera was mounted below the actuator in these tests, allowing us to verify that gapping did occur, in contrast to results presented by Jeanjean et al [28]. However, it is believed that due to the consolidation method of the study, the top of the soil could have acted as an over-consolidated clay, inducing easy formation of gaps. An example of a gap can be observed in Fig. 8.

Regarding boundary conditions, the pile was displaced laterally to produce failure. The applied displacement is located at a point above the mudline at an eccentricity of $1.4 \mathrm{D}$. The pile has been constrained against vertical displacement to simulate the test setup. Besides these two constraints, the pile is free to move in any direction. The bottom of the mesh was constrained against vertical displacement whilst the far ends (i.e. circumference) were constrained in both $X$ and $Y$ horizontal directions, with infinite elements included around the circumference of the soil cylinder.

For comparison with centrifuge experiments, data is presented in terms of normalized capacity at the load application point: the lateral resultant $\left(F_{h}\right)$ divided by the product of the average undrained shear strength along the pile $\left(s_{u-a v g}\right)$ and the projected area of the pile, as presented in (8). Contours of displacement magnitude are presented in Fig. 9. It can be observed that the developed failure mechanism is in very good agreement with the one proposed by Murff and Hamilton [16] and modified by Randolph and House [29], which include the presence of a semi-conical passive wedge, combined with a spherical failure surface at the bottom of the pile. There is no active wedge; instead, the gap can be clearly appreciated forming behind the pile, as it is displaced in the right $(+X)$ direction.

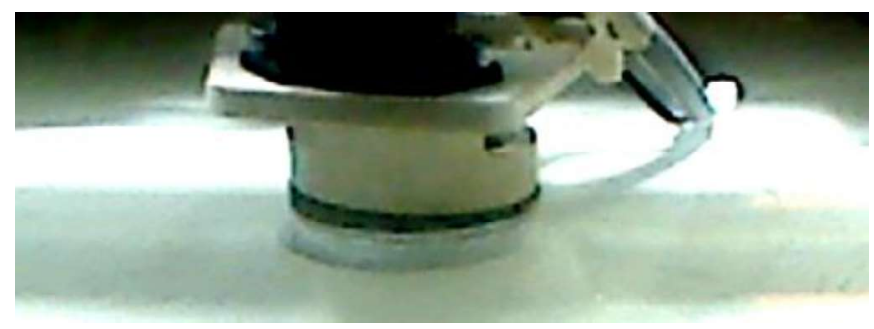

Fig. 8. Evidence of a small gap. Pile is being displaced to the right

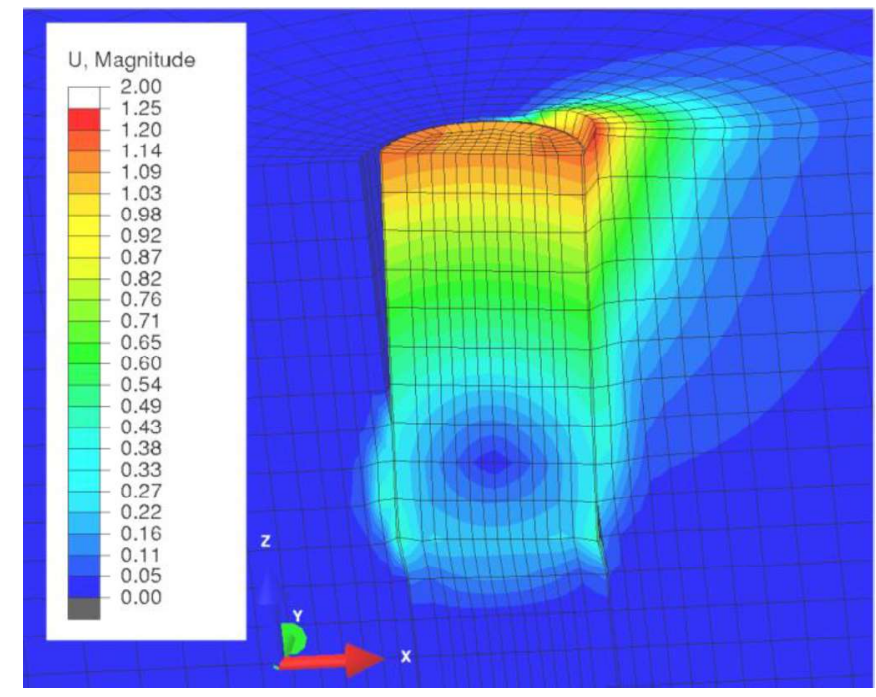

Fig. 9. Finite element mesh. Deformed configuration, displacement contours.

\section{RESULTS AND DisCUSSION}

Load-displacement curves are presented in Fig. 10 for piles $\mathrm{R} 1$ and R2 along with finite element predictions, in blue lines. Table II presents a written summary of the configuration and results obtained.

Pile R1, presented as red circles, exhibits a reasonable trend and reaches an ultimate capacity of approximately $N_{h}=0.9$, at a normalized displacement $(y / D)$ of around 0.15 . After this point, data seems to show a small decrease in capacity, thought to be possibly due to drained conditions starting to develop. However, similar behaviors have also been observed in previous studies [7, 30].

Pile R2 is presented as green squares. Data corresponds to a remolded test what was performed after the initial loading. During initial stages of the test (i.e. virgin loading) one of the strain gauges had a temporary electrical fault. As a result, no satisfactory readings were obtained. Fortunately, as the pile was loaded backwards, the strain gauge started working properly, making it possible to carry a remolded test. As observed in Fig. 10, Pile R2 develops an ultimate capacity of approximately 1.05 at a normalized displacement $y / D \approx 0.04$, after which some softening and re-hardening is observed.

TABLE II.

PILE RESULTS AND INFORMATION

\begin{tabular}{|l|l|l|}
\hline \multicolumn{1}{|c|}{ Pile } & \multicolumn{1}{|c|}{ R1 } & \multicolumn{1}{c|}{ R2 } \\
\hline Diameter/Length, mm & $50 / 100$ & $50 / 100$ \\
\hline $\begin{array}{l}\text { Centre of rotation, } \\
\text { mm below mudline }\end{array}$ & 45 & 65 \\
\hline Tilt, deg & 4.5 & 9 \\
\hline $\mathrm{b}, \mathrm{mm}$ & 30 & 34 \\
\hline$l, \mathrm{~mm}$ & 110 & 130 \\
\hline $\mathrm{M}_{\mathrm{k}}, \mathrm{kN}-\mathrm{m}$ & 340 & 420 \\
\hline $\mathrm{N}_{\mathrm{h}}$ & 0.92 & 1.05 \\
\hline $\mathrm{N}_{\mathrm{m}}$ & 1.01 & 1.31 \\
\hline
\end{tabular}




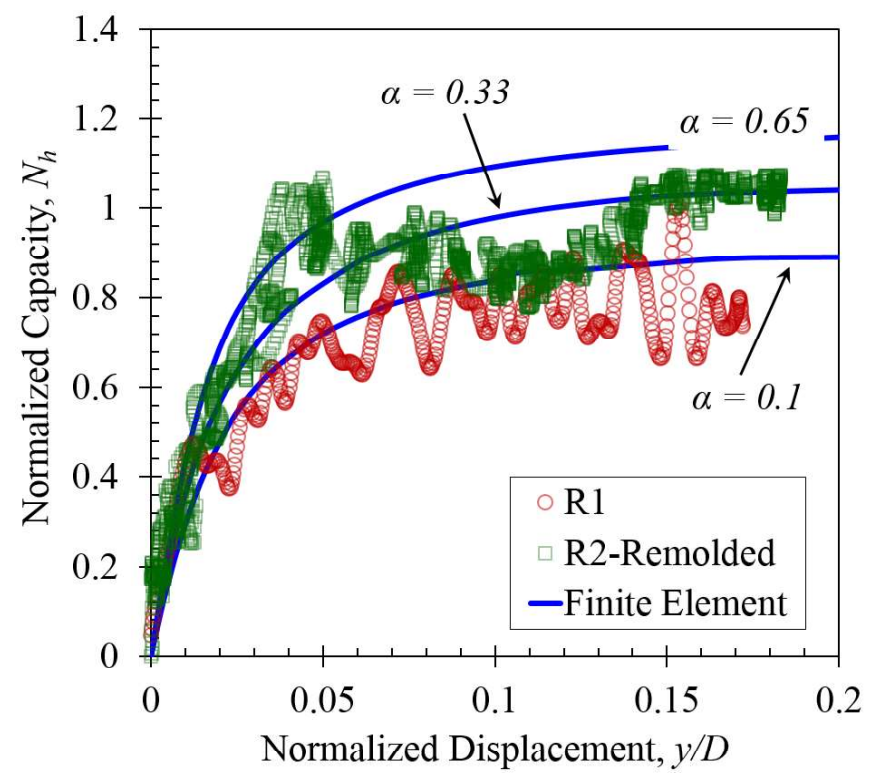

Fig. 10. Comparison between experimental data and FEA predictions

Although a previously mentioned adhesion $(\alpha)$ of 0.65 was recommended in the finite element analysis, it was found that predictions for this adhesion were somewhat higher than the experimental results. Lower adhesions were therefore considered. Adhesions ranging between 0.1 and 0.33 encompassed maximum values during testing, with most of the values for pile R1 being in agreement with the lower bound ( $\alpha$ $=0.1$, whilst results from test R2 compares better to FEA predictions for $\alpha=0.33$.

Despite the agreement between FEA and experimental results, an adhesion of 0.1 is believed to be too low. This potentially implies that the FEA does not fully capture the behavior of piles with gapping. However, the experimental values presented here are also lower than 1-g laboratory tests performed at Texas A\&M University, on piles of similar aspect ratios and eccentricities [15, 24]. Beemer [24] measured normalized capacities around $N_{h}=1.2$, which compare relatively well with FE predictions for adhesion of 0.65 . Table III presents lateral capacity values of Beemer [24], Murali [11], and $\mathrm{Lau}[6]$ as a comparison for this pile to other similar tests. Lau shows a higher capacity, but at a higher aspect ratio that is to be expected. While the vertical load in this work accounts for some of the low capacity values, comparisons to Beemer [24] and Murali [11] raise concerns of whether the loading system was too compliant, and opens doors for more experiments to be performed for verification.

Data from Table III is plotted in Fig. 11 along with predictions using simplified limit analysis as presented by Grajales et al. [31], for the case of a gap forming behind the pile. Such predictions were made using a solution proposed by Aubeny et al. [32] for the case of a laterally loaded pile with varying eccentricities. Fig. 11 shows that data from this experimental program plot below the predicted values for no adhesion. However, the agreement is considered fair when taking into account that piles tested for this work were restricted against vertical movement and, thus, a vertical force developed in the stem.
TABLE III.

COMPARISONS TO PREVIOUS WORK

\begin{tabular}{|c|c|c|c|}
\hline Work & Aspect Ratio & Eccentricity & Capacity \\
\hline R1 & 2 & 1.4 & 0.85 \\
\hline R2 & 2 & 1.4 & 1.05 \\
\hline Beemer [24] & 2 & 1.4 & 1.2 \\
\hline Murali [11] & 2 & 1.5 & 1.5 \\
\hline Lau [6] & 4.75 & 0.1 & 3.8 \\
\hline
\end{tabular}

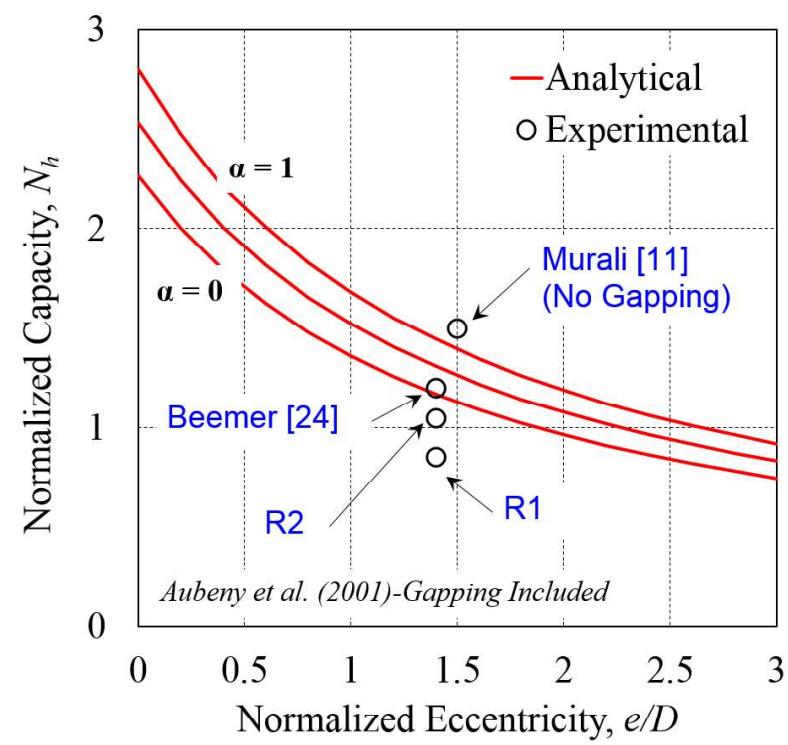

Fig. 11. Comparison between experimental data and analytical solution by Aubeny et al. [31]

\section{FINAL REMARKS}

Results from geotechnical centrifuge testing have been presented for piles with an aspect ratio of 2, free to rotate, loaded eccentrically, and vertically restricted. Centrifuge results have been compared to predictions from finite element analyses, designed for conditions similar to the testing environment.

Results show a relatively good comparison between FE predictions and measured capacities. FE results indicate normalized bearing capacities on the range of $N_{h}=0.8$ to 1 for limiting adhesions of $\alpha=0.1$ and 0.33 . Piles R1 and R2 produced normalized capacities around 0.85 and 1.05, respectively. This validated the FE model, which had previously predicted pile capacities accurately under 1-g conditions.

Contrary to previous centrifuge studies [11, 28], gapping was observed during these tests (Fig. 8). The observed gap was essentially a very small crack behind the pile. The gap could have occurred because the clay was slightly over-consolidated at initial depths due to the weight applied on top during preconsolidation. The existence of a gap is supported by the fact that FE simulations had to be configured to model the gap phenomenon to obtain reasonable agreement with the experimental data.

Compared to higher aspect ratios [6], squat piles with aspect ratios, $L / D=2$ are inefficient for supporting higheccentricity lateral and moment loading. However, for smaller 
structures with lower lateral moments, squat piles could provide a relatively inexpensive solution in configurations such as tripods and tetrapods, in which most of the lateral loads are transmitted as axial reactions to the foundation system.

Finally, results have been compared to predictions obtained using a simplified plastic limit analysis method [31, 32]. Results suggest that the simplified PLA method tends to overpredict capacities when compared to the tested piles. However, the curves presented (Fig. 11) do not include application of vertical load, which was present during testing.

\section{ACKNOWLEDGMENTS}

The authors would like to acknowledge the support provided by the National Science Foundation (USA), the National Secretary of Science and Technology (Panama), and the technical personnel at the University of Cambridge.

\section{REFERENCES}

[1] Poulos, H., \& Davis, E. (1991). Elastic solutions for soil and rock mechanics. Sydney, Australia: Centre for Geotechnical Research, University of Sydney.

[2] Randolph, M. (1981). The response of flexible piles to lateral loading. Geotechnique, 31(2), 247-259.

[3] Matlock, H (1970). Correlations for Design of Laterally Loaded Piles in Soft Clay. Proc. Offshore Tech. Conf. (pp. 577-588). Houston.

[4] Hoadley, P. J., Barton, Y. O., Parry, R. H. (1981). Cyclic lateral load on model pile in a centrifuge. 10th Int'l Conf. on Soil Mechanics and Foundation Eng. Stockholm.

[5] Mayne, P., Kulhawy, F., Traugmann, C. (1995). Laboratory Modeling of Laterally-Loaded Drilled Shafts in Clay. Journ. of Geotech. Eng., $121(12), 827-835$.

[6] Lau, B. H. (2015). Cyclic Behavior of Monopile Foundations for Offshore Wind Turbines in Clay. Ph. D Thesis, Cambridge University, Cambridge, UK.

[7] Zhang, C., White, D., \& Randolph, M. (2011). Centrifuge Modeling of the Cyclic Lateral Response of a Rigid Pile in Soft Clay. Journ. of Geotech. and Env. Eng., 137(7), 717-729.

[8] Houlsby, G. T. , Kelly, R. B., Huxtable, J, \& Byrne, B. W. (2005). Field trials of suction caissons in clay for offshore wind turbine foundations. Geotechnique, ICE, 55(4), 287-296.

[9] Zhu, B., Kong, D.-q., Chen, R.-p. Kong, L.-g., \& Chen, Y.-m. (2011). Installation and lateral loading tests of suction caissons in silt. Canadian Geotech. Journ., 1070-1084

[10] Brødbæk, K., Møller, M., Sørensen, S., \& Augustesen, A. (2009). Review of p-y relationships in cohesionless soil. DCE Technical Report No. 57, Aalborg University, Department of Civil Engineering, Aalborg.

[11] Murali, M. (2015). Characterization of Soft Clays and the Response of Soil Foundation Systems for Offshore Applications. Ph. D. Thesis, Texas A\&M University, College Station, Texas, USA.

[12] Brown, D., Shie, C. (1990). Three-dimensional finite element model of laterally loaded piles. Computers and Geotechnics, 10(1), 59-79.
[13] Trochanis, A., Bielak, J., Christiano, P. (1991). Three-dimensional nonlinear study of piles. Journ. of Geotech. Eng., 117(3), 429-442.

[14] Kim, Y., Jeong, S. (2011). Analysis of soil resistance on laterally loaded piles based on 3D soil-pile interaction. Computers and Geotechnics, $38(2), 248-257$.

[15] Grajales, F. (2017). Lateral capacity of piles and caissons in cohesive soils.. Ph. D Dissertation, Civil Engineering, Texas A\&M University, College Station.

[16] Murff, J., \& Hamilton, J. (1993). P-ultimate for undrained analysis of laterally loaded piles. Journ. of Geotech. Eng., ASCE, 119(1), 91-107.

[17] Stevens, J.B., Audibert, J.M.E., 1980. Re-examination of p-y curve formulation, Proceedings of Eleventh Offshore Technology Conference, Houston, OTC 3402, 397-403.

[18] Randolph, M., \& Houlsby, G. (1984). The limiting pressure on a circular pile loaded laterally in cohesive soil. Geotechnique, 34(4), 613-623.

[19] Martin, C., \& Randolph, M. (2006). Upper-bound analysis of lateral pile capacity in cohesive soil. Geotechnique, 56(2), 141-145.

[20] Ladd, C., \& Foott, R. (1974). New Design Procedure for Stability of Soft Clays. Journ. of Geotech. Eng., 100(7), 763-786.

[21] Skempton, A. (1954). Discussion: sensitivity of clays and the $\mathrm{c} / \mathrm{p}$ ratio in normally consolidated clays. Proc. of the American Society of Civil Engineers, 19-22.

[22] Skempton, A. (1957). Discussion: further data on the $\mathrm{c} / \mathrm{p}$ ratio in normally consolidated clays. Proc. of the Inst. of Civil Engineers, 7, 305-307.

[23] Haigh, S., Houghton, N., Lam, S., \& Wallbridge, P. (2010). Development of a 2D servo-actuator for novel centrifuge modelling. 7th Int'l Conf. on Physical Modelling in Geotech. 1, pp. 239-244. CRC Press/Balkema.

[24] Beemer, R. (2015). Experimental Studies of Squat Gravity Caissons and Monopiles for Offshore Applications. Ph. D Thesis, Texas A\&M University, College Station.

[25] Simulia. Abaqus v6.12. User Manual.

[26] Vesic, A.S. (1972). Expansion of cavities in infinite soil mass. ASCE Journ. of the Soil Mech. and Found. Div. 98(3), pp. 265-290

[27] Andersen, K. and Joostad, H. (2002). Shear strength along outside wall of suction anchors in clay after installation. Proceedings of the $12^{\text {th }}$ ISOPE Conference, Kyushu, Japan. Pp.785-794

[28] Jeanjean, P., Znidarcic, D., Phillips, R., Ko, H.-Y., Pfister, S, Cinicioglu, B., and Schroeder. (2006). Centrifuge testing on suction anchors: double wall, over-consolidated clay, and layered soil profile. Proceedings of the Offshore Technology Conference. Houston, Texas

[29] Randolph, M. and House, A.R. (2002). Analysis of suction caisson capacity in clay. Proceedings of the Offshore Technology Conference. Houston, Texas.

[30] Coffman, R.A., El-Sherbiny, R.M., Rauch, A.F. and Olson, R. (2004). Measured horizontal capacity of suction caissons. Proceedings of the Offshore Technology Conference. Houston, Texas.

[31] Grajales, F.J., Beemer, R.D., Murali, M., Aubeny, C.P. and Biscontin, G. (2015). Response of short monopiles for offshore wind turbine foundations: virgin and post-cyclic capacity. Proceedings of the $68^{\text {th }}$ Canadian Geotechnical Conference, Quebec City, Canada

[32] Aubeny, C.P., Murff, J.D. and Moon, S. (2001). Lateral undrained resistance of suction caisson anchors. International Journal of Offshore and Polar Engineering. 11(3), 211-219. 